\title{
Socioeconomic Impact of RSV Hospitalization
}

Michal Young $\cdot$ Lynn Smitherman

Received: December 8, 2020 / Accepted: December 9, 2020 / Published online: March 3, 2021

(C) The Author(s) 2021

\section{ABSTRACT}

Respiratory syncytial virus (RSV) disease is a significant cause of morbidity and socioeconomic burden worldwide among young children. The majority of RSV-associated lower respiratory tract infections (LRTI) and mortality occurs in developing countries and is associated with various sociodemographic risk factors. Independent risk factors for severe RSV disease include age and premature birth. While RSV mortality in developed countries is lower relative to developing countries, high-risk infants with comorbidities experience higher rates of mortality. RSV LRTI is often severe and is associated with hospitalization, increased need for intensive care unit admission and mechanical ventilation, long-term complications, and caregiver stress and loss of work productivity. Overall, these factors translate to higher health care resource utilization and costs and should be factored into the consideration for RSV prophylaxis. Multiple vaccine candidates and longacting monoclonal antibodies are in various stages of clinical development. Currently, palivizumab is the only approved RSV immunoprophylaxis available for use in specific highrisk pediatric populations. This review will discuss the socioeconomic impact and health care resource utilization of RSV-related hospitalization (RSVH) as well as various sociodemographic risk factors that can be used to identify children at high risk of developing severe RSV disease.

Keywords: Caregiver burden; Cost-effectiveness; Health care utilization; High-risk infants; Immunoprophylaxis; Palivizumab; Quality of life; Risk-factor predictive model; RSV-related hospitalization; Socioeconomic factors
M. Young ( $\square)$

Department of Pediatrics and Child Health, Howard University Hospital, Washington, DC, USA

e-mail: m_a_young@Howard.edu

L. Smitherman

Department of Pediatrics, Wayne State University

School of Medicine, Detroit, MI, USA 


\section{Key Summary Points}

Respiratory syncytial virus (RSV) disease is a global concern and is a cause of significant morbidity and socioeconomic burden among high-risk populations

Physician and emergency department visits, hospitalization, intensive care unit admission, need for mechanical ventilation, cost associated with treatment, caregiver stress and work loss, and long-term complications all contribute to the increasing health care utilization and economic burden of RSV disease

Although development of a vaccine against RSV has been a global priority for several decades, no vaccines are currently available; palivizumab is the only licensed RSV prophylaxis available to prevent severe RSV disease in high-risk infants and children

Clinical efficacy of palivizumab in preventing severe RSV disease is well established

Until additional safe and effective preventive therapies for RSV become available, palivizumab should be used for high-risk patients, and adoption of strategies to help promote costeffectiveness should be employed

\section{DIGITAL FEATURES}

This article is published with digital features, including a summary slide, to facilitate understanding of the article. To view digital features for this article go to https://doi.org/10.6084/ m9.figshare.13333388.

\section{INTRODUCTION}

Respiratory syncytial virus (RSV) disease is a leading cause of hospitalization associated with lower respiratory tract infections (LRTI) among infants aged $<1$ year [1]. The disease is generally self-limiting with upper respiratory tract symptoms in otherwise healthy infants and adults; however, $20-30 \%$ of infants develop LRTI such as bronchiolitis and pneumonia $[2,3]$. Elderly adults have a higher rate of pneumonia and long-term mortality within 1 year of RSV-related hospitalization (RSVH) than those infected with influenza [4]. Severe RSV infection is characterized by cough, wheezing, tachypnea, dyspnea, otitis media, chest wall retractions, and cyanosis [2, 3]. Populations at increased susceptibility to severe RSV infection include infants born prematurely; children with comorbidities such as chronic lung disease of prematurity (CLDP, formerly known as bronchopulmonary dysplasia [BPD]), congenital heart disease (CHD), immunodeficiency, cystic fibrosis, or chromosomal abnormalities such as Down syndrome; adults aged $\geq 65$ years; and adults with immunosuppression [3, 5]. RSV-infected infants often require hospitalization, intensive care unit (ICU) admission, and mechanical ventilation with longer hospital stays. Moreover, they have higher rates of physician visits and develop long-term morbidities such as bronchospasm and asthma. Overall, these factors contribute to substantial health care utilization and economic burden of RSV disease [6].

Despite continued efforts for several decades, there is no effective cure or approved RSV vaccine. Development of an RSV vaccine is a global priority, and there are several other promising candidates for RSV disease management, including antivirals and extended half-life monoclonal antibodies, which will be discussed in the next article. It will be several years before safe and effective RSV therapies become available in clinical practice [7]. Until then, palivizumab, a humanized monoclonal antibody, is the only licensed immunoprophylaxis available to prevent severe RSV LRTI in specific high-risk pediatric populations, including premature infants ( $\leq 35$ weeks' gestational age [wGA]) aged $\leq 6$ months, children with BPD aged $\leq 24$ months, and children with hemodynamically significant CHD aged $\leq 24$ months $[7,8]$. This review will discuss the various 
sociodemographic risk factors that can be used to identify infants at high risk of developing severe RSV disease, long-term burden of severe $\mathrm{RSV}$, the impact on caregivers, and health care resource utilization. This article is based on previously conducted studies and does not contain any studies with human participants or animals performed by any of the authors.

\section{GLOBAL BURDEN OF RSV DISEASE}

RSV is the most common cause of LRTI in young children and is associated with high morbidity and mortality. Globally, RSV accounts for approximately 33 million LRTI episodes, 3 million RSVH, and 60,000 deaths among children aged $<5$ years [9]. Of note, more than $90 \%$ of RSV LRTI and mortality occur in developing countries, commonly involve otherwise healthy term infants, and are often associated with serious respiratory and systemic infections and pneumothoraxes $[9,10]$. Overall, RSV disease is a significant cause of mortality and respiratory failure among infants in lowincome regions of developing countries potentially because of limited availability of diagnostic tests and access to health care. In developed countries, although mortality owing to severe RSV disease is rare, it typically occurs in high-risk infants with comorbidities [10].

RSV incidence and mortality rate vary from season to season depending on geographic location and socioeconomic and environmental factors [9, 11]. An 18-year RSV surveillance study conducted in Alaskan Native infants reported that the RSVH rate was three times higher in this population than in the rest of the USA, despite an overall decline in RSVH rates by $60 \%$ and a shorter RSV season. Socioeconomic factors that were associated with these higher RSVH rates included overcrowded living conditions and limited availability of indoor plumbing [12]. An evidence-based systematic review, REGAL (RSV Evidence-a Geographical Archive of the Literature), provided a comprehensive analysis of studies conducted between 1995 and 2015 on RSV disease burden in Western countries, including the USA, Canada, and Europe. Among infants and children, RSV accounted for
$12-63 \%$ of all acute respiratory infections, led to $19-81 \%$ of all viral acute respiratory infectionassociated hospitalizations, and was associated with $<0.5 \%$ mortality [13]. Severity of RSVH also varies geographically and the length of hospital stay ranges between 1.2 and 15 days. The average hospital stay was 5-8 days in Spain and 1.2-3.8 days in the USA/UK; the proportion requiring ICU admission was estimated to be $1.5 \%$ in Spain, $3.6 \%$ in Israel, and $11.6-17.5 \%$ in the USA. While there is no direct explanation for the varying trends between countries, it should be noted that the presence of co-infection and/or comorbidities can influence the severity of RSV infection, including length of hospital stay and ICU admission [6].

In contrast to the vast literature on pediatric populations, epidemiologic data on adult and elderly populations are limited. Globally, severity and burden of RSV disease among adults and the elderly are comparable to that of influenza with higher mortality rates occurring among individuals with immunosuppression and those requiring hospitalization [6]. A global systematic review that included 44 studies reported annual RSVH rates per 1000 persons $(95 \%$ CI $)$ of $1.0(0.5-2.1)$ in industrialized countries and $0.3(0.1-0.7)$ in developing countries; in-hospital mortality per 1000 cases $(95 \% \mathrm{CI})$ are $3.3(1.0-10.8)$ in industrialized countries and $10.1(2.1-45.5)$ in developing countries [14]. It should be noted that underestimation of RSV burden could occur as a result of misdiagnosed or unrecognized RSV infection owing to similar clinical presentation of RSV and influenza [6]. However, RSV burden could be overestimated as well, as milder cases are not rigorously tested compared with cases requiring hospitalization [15].

A recent US, observational, retrospective, industry-sponsored cohort study conducted by Ackerson et al. compared mortality and morbidity in adults aged $\geq 60$ years who were hospitalized because of RSV $(n=645)$ or influenza $(n=1878)$ infections. Compared with influenza-infected patients, those with RSV infection had 2.7 times $(P<0.001)$ higher risk of developing pneumonia and significantly higher odds of chronic obstructive pulmonary disease exacerbation, requiring ICU admission, longer 
hospital stay, and higher mortality within a year following infection [4]. Globally, RSV disease has a substantial medical burden with varying morbidity and mortality, depending on geographic and socioeconomic factors [6].

\section{SOCIODEMOGRAPHIC RISK FACTORS ASSOCIATED WITH RSV DISEASE}

Several sociodemographic factors contribute to the risk of developing severe RSV disease. Recognition of these factors can help identify high-risk populations, inform policy makers of effective management strategies, and educate parents and other caregivers regarding modifiable risk factors $[16,17]$. Importantly, younger chronologic age is an independent risk factor for RSV disease, and almost all children are infected by 2 years of age $[5,18]$. In a comprehensive, global, systematic review of 27 studies, Shi et al. identified premature birth, low birth weight, male sex, presence of siblings, maternal smoking, family history of atopy, lack of breast-feeding, and overcrowded household (>7 members) as risk factors that are significantly associated with severe RSV disease among children aged $<5$ years (Table 1 ). Reduced parental education, exposure to smoking, day care attendance, indoor air pollution, HIV, multiple gestation, malnutrition, altitude, history of illness, and limited availability of indoor plumbing may also increase the risk of RSV-associated LRTI [16]. Nutritional status and poor infant growth can be positive predictors of RSVH, especially in non-industrialized regions, and may also confound the efficacy analysis of palivizumab [16, 19].

In the USA, public vs private insurance is an independent factor that is associated with an increased risk of RSVH and a twofold higher rate of emergency department visits among 32-35 wGA infants [20]. Other risk factors with minor association to RSVH among children aged $\leq 18$ years include high altitude, cesarean delivery, and black or aboriginal race [13]. In low-income, developing regions, there are numerous risk factors significantly associated $(P \leq 0.05)$ with severe RSV disease leading to
Table 1 Multivariable and univariable analysis of risk factors for RSV [16]

\begin{tabular}{|c|c|c|}
\hline Risk factor & $\begin{array}{l}\text { No. of } \\
\text { studies }\end{array}$ & $\begin{array}{l}\text { Odds ratio } \\
\text { (95\% confidence } \\
\text { interval) }\end{array}$ \\
\hline $\begin{array}{l}\text { Prematurity (gestational } \\
\text { age }<37 \text { weeks) }\end{array}$ & 7 & $1.96(1.44-2.67)$ \\
\hline Low birth weight & 5 & $1.91(1.45-2.53)$ \\
\hline Being male & 12 & $1.23(1.13-1.33)$ \\
\hline Siblings & 11 & $1.60(1.32-1.95)$ \\
\hline Maternal smoking & 7 & $1.36(1.24-1.50)$ \\
\hline History of atopy & 5 & $1.47(1.16-1.87)$ \\
\hline Low parental education & 6 & $1.40(0.94-2.08)$ \\
\hline Passive smoking & 8 & $1.29(0.96-1.73)$ \\
\hline $\begin{array}{l}\text { Day care center } \\
\text { attendance }\end{array}$ & 3 & $1.61(0.98-2.64)$ \\
\hline Indoor air pollution & 5 & $0.81(0.42-1.57)$ \\
\hline No breast-feeding & 3 & $2.24(1.56-3.20)$ \\
\hline $\begin{array}{l}\text { Crowding ( }>7 \text { persons in } \\
\text { household) }\end{array}$ & 3 & $1.94(1.29-2.93)$ \\
\hline
\end{tabular}

respiratory failure or mortality among infants aged $<1$ year, including chronologic age $\leq 6$ months; prematurity; low birth weight; presence of comorbidities such as cardiac disease or neurologic disease; Down syndrome; male sex; lack of breast-feeding; respiratory support during neonatal period; presence of clinical complications such as pneumonia, sepsis, positive blood culture, and pneumothorax; and environmental factors such as exposure to tobacco smoke and lack of a sewage system at home [10]. In general, the presence of $\geq 2$ factors is a strong predictor of RSVH risk [6]. Region-specific customization of risk factors should be used to identify populations at high risk for severe RSV disease and to effectively mitigate its global burden $[16,21]$. 


\section{IMPACT OF RSVH ON CAREGIVERS}

In addition to morbidity among affected patients, RSVH causes significant distress among caregivers of patients with RSVH. In a prospective study, Leidy et al. analyzed the burden of RSVH on caregivers of 46 premature infants $(\leq 35 \mathrm{wGA})$ and children aged $\leq 30$ months. Significant distress was observed among patients and caregivers during the period of RSVH (average length of stay, $5.8 \pm 8$ days) that lasted up to 60 days after discharge. This burden manifested as high stress, poor functional status, and poor overall health among patients and high stress, anxiety, and disruption of family health and routines among caregivers compared with controls [22].
The findings were further confirmed in a recent secondary analysis based on the SENTINEL1 study that assessed the burden of RSVH among caregivers of hospitalized 29-35 wGA infants aged $<1$ year and who did not receive RSV immunoprophylaxis $(N=702)$ during the 2014-2015 RSV season. Stress among caregivers (self-reported) and infants (perceived by caregiver) was high and persisted for at least 1 month post-discharge (Fig. 1). This was accompanied by missed work and decreased work productivity (91\% and $31 \%$ in mothers and $81 \%$ and $18 \%$ in fathers at discharge and 1 month post-discharge, respectively), disruption of sleep and family routines, separation from siblings, and strain in finances and family relationships. In general, the impact was higher

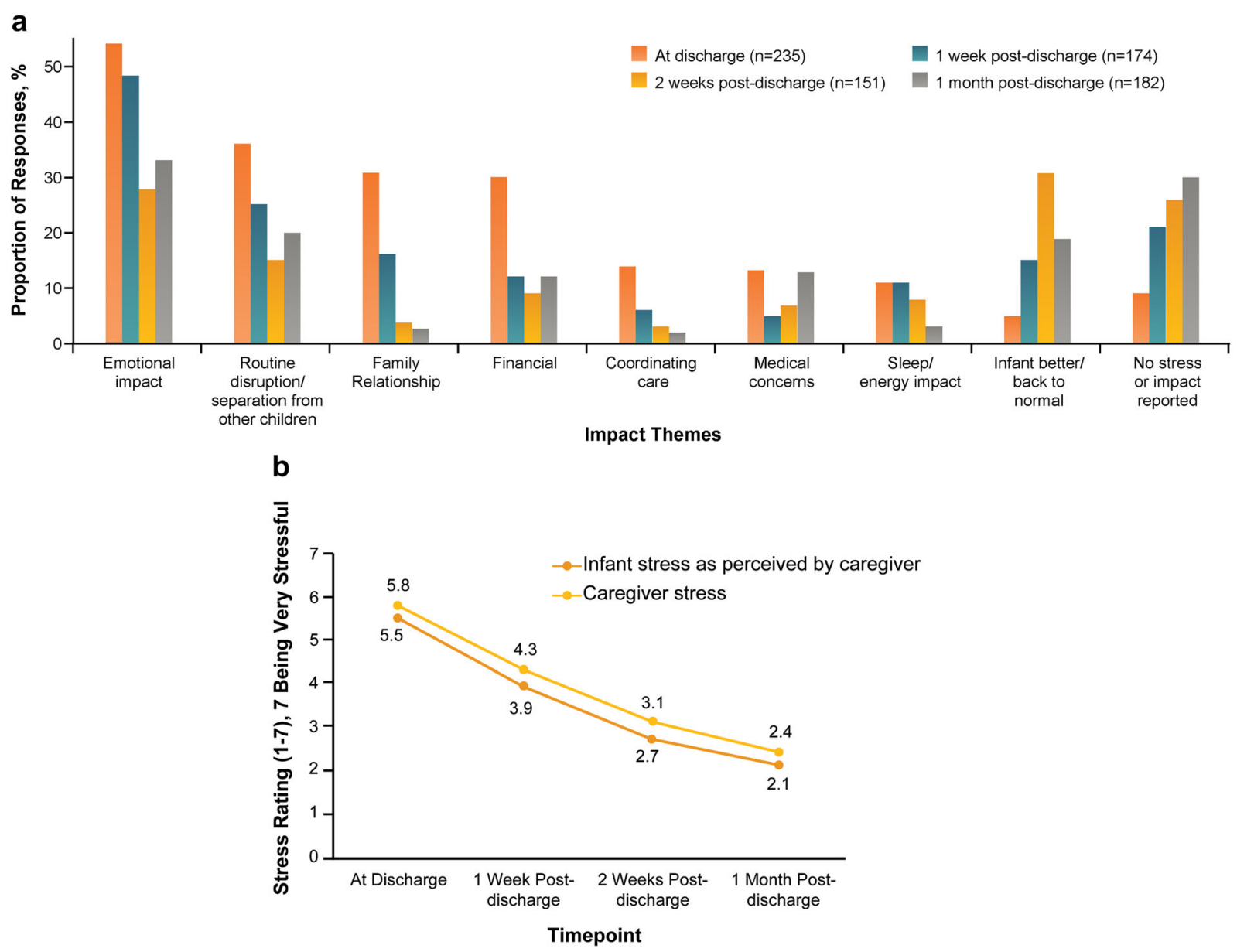

Fig. 1 a Impact of RSV hospitalization on caregivers persisted following discharge; $\mathbf{b}$ Caregiver-reported stress is high and can persist after RSVH [23]. RSV respiratory syncytial virus, RSVH RSV-related hospitalization From Pokrzywinski RM, et al. Clin Pediatr (Phila). 2019;58(8):837-850 
among caregivers of infants born at an earlier gestational age [23]. Overall, the impact of RSVH among caregivers and infants is substantial and should not be underestimated.

\section{LONG-TERM IMPACT OF RSV DISEASE}

In addition to the short-term morbidity associated with severe RSV disease, RSV LRTI in early childhood is a significant risk factor for the development of recurrent wheezing, asthma, and impaired lung function later in life. In the REGAL systematic literature review (21 studies), recurrent wheezing rates of $4-47 \%$ and asthma rates of $8-76 \%$ were reported later in life in children who experienced an episode of RSV LRTI at the age of $<3$ years (followed up to 25 years). These long-term morbidities may be due to RSV itself or to the presence of preexisting and predisposing factors related to wheezing and asthma and other environmental risk factors [24].

In a recent global systematic literature review of 10 retrospective studies and 31 prospective studies conducted between 1995 and 2018, Shi et al. reported that an RSV LRTI in children aged $<3$ years was significantly associated with the development of recurrent wheezing and asthma vs the control group without childhood respiratory insult (followed up to 9 years). An early childhood RSV infection increased the risk of wheezing by 3.05 times during the first 36 months, 2.60 times during 36-72 months, and 2.14 times during 73-144 months of follow-up compared with the control group. Similarly, the risk of asthma development was estimated to be 2.95 times greater for 73-144 months following an RSV LRTI compared with the control group [25]. Recurrent wheezing, which manifests more during the winter months, can negatively affect quality of life directly through respiratory symptoms, sleep disturbances, and/or gastrointestinal symptoms [6]. Asthma and recurrent wheezing are also associated with substantial, long-term, financial (both direct and indirect) and societal burdens; the mean annual expenditure for a patient with asthma may be more than $\$ 5000$
$[25,26]$. Long-term sequelae of RSV disease, including recurrent wheezing and asthma, account for $10-18 \%$ of health care resource utilization and add to the economic burden of RSV disease [27, 28]. Although the association between early RSV LRTI and long-term complications is significant, a causative role for RSV in wheezing and asthma is difficult to establish and a mechanism has not been identified [25].

RSV prophylaxis with palivizumab in childhood may have a role in reducing the rate and onset of long-term RSV disease sequelae. In the industry-sponsored, placebo-controlled MAKI trial, Blanken et al. showed that monthly palivizumab prophylaxis in 429 infants born at 33-35 wGA during the RSV season reduced the number of wheezing days by $61 \%$ (1.8\% vs $4.5 \%$ with a modest reduction of 2.7 days per 100 days) and the proportion of infants with recurrent wheezing $(11 \%$ vs $21 \% ; P=0.01)$ in the first year of life compared with placebo [29]. Another industry-sponsored trial $(N=440)$ also showed decrease in wheezing among palivizumab recipients vs non-recipients $(6.4 \%$ vs $18.9 \% ; P<0.001)$ during the study follow-up period (until the third birthday of enrolled children); however, the study had a non-randomized, observational design [30]. Additional well-controlled studies with standardized definitions and parameters are needed to ascertain the preventive role of RSV prophylaxis in wheezing and asthma and further inform RSV management guidelines for high-risk individuals [25]. Palivizumab is not currently indicated to reduce recurrent wheezing and asthma [8].

\section{IMPACT OF RSV DISEASE ON HEALTH CARE UTILIZATION}

Health care utilization for RSV disease includes visits to primary care physicians and specialists, emergency department visits, hospital and ICU admissions, diagnostic tests for RSV infection, and management of RSV, including oxygen, mechanical ventilation, antibiotics, and RSV prophylaxis [6]. In general, RSVH and its severity, as measured by ICU admission, need for mechanical ventilation, and length of stay tend to be higher among high-risk infants with 
earlier gestational age and younger chronologic age $[6,31,32]$. In the USA, RSV disease alone accounts for $2.2 \%$ of all primary care visits, $3.2 \%$ of visits to a specialist, and $4.1 \%$ of emergency department visits in children aged $<5$ years [33]. Proportions of RSVH and its severity are generally higher for preterm infants (born at $\leq 35 \mathrm{wGA}$ ) compared with term infants. Estimates of RSVH are also higher for those born at earlier gestational age and with younger chronologic age. In the USA, rates of RSVH range between $1.5 \%$ and $3.8 \%$ for preterm infants and $0.9 \%$ and $1.6 \%$ for term infants aged $<1$ year. RSVH may require ICU admission in more than half of preterm infants aged $<90$ days (range, $21 \%-58 \%$ by wGA), a much higher proportion than for term infants (11\%). Mechanical ventilation use can be required for as many as $34 \%$ and $14 \%$ of cases among preterm infants aged < 90 days and $<1$ year, respectively; for term infants, the respective estimates are $2 \%$ and $3 \%$ [32]. The proportion of RSVH during the neonatal period is higher among preterm infants (as high as $26.2 \%$ in $<29$ wGA infants) relative to term infants (3.3\%) and further increases as the GA decreases. In addition, preterm infants require increased hospitalization length of stay, number of outpatient visits, pharmacy claims, and mean monthly health care costs (Fig. 2) compared to term infants [34].

Data from SENTINEL1 showed that RSVH is often severe in high-risk 29-35 wGA infants not receiving RSV immunoprophylaxis. The proportion of $29-35 \mathrm{wGA}$ infants aged $<1$ year with RSVH who required ICU admission and mechanical ventilation use was $45 \%$ and $19 \%$, respectively. These resources substantially contributed to the direct medical costs of RSVH with the highest charges incurred by 29-32 wGA infants aged $<3$ months (median hospital charges, $\$ 77,209)$. In general, both health care utilization and costs were higher when RSVH was associated with ICU admission, mechanical ventilation use, and increased length of stay [31]. In a retrospective, claimsbased study, McLaurin et al. analyzed 1,683,188 Medicaid-insured (MED) infants and 1,663,832 commercially insured infants (COM) born between 2003 and 2013, of whom 10.8\% and
$8.8 \%$, respectively, were born prematurely $(<36$ wGA). The mean hospitalization cost in the first year following RSVH was higher for preterm infants (MED, \$15,839 and COM, $\$ 19,931$ for 33-34 wGA infants; MED, \$39,354 and COM, $\$ 40,813$ for $<29$ wGA infants) vs term infants (MED, \$8324 and COM, \$10,570) [32].

In a recent retrospective observational cohort, Ledbetter et al. estimated health care utilization and costs that were incurred in the first year following RSVH relative to controls (no LRTI-related hospitalization) (MED, 1,008,040 infants; COM, 703,945 infants). Health care utilization and costs were significantly higher among the RSVH group compared with the control group, and this was further increased for preterm infants vs term infants and those born at earlier gestational age. The highest mean health care costs were incurred by $<29$ wGA infants with RSVH (MED, \$89,202; COM, \$263,509) and the lowest were among term infants in the control group (MED, \$1286; COM, \$2804) [35]. Overall, severe RSV disease and its associated short-term and long-term costs pose significant economic burdens.

Well-controlled industry-sponsored clinical trials have shown that palivizumab reduces RSVH by $78 \%, 39 \%$, and $45 \%$ in $\leq 35 \mathrm{wGA}$ infants, children with BPD, and CHD, respectively $[29,36,37]$. While various studies have examined the cost-benefit of palivizumab, the results are inconclusive [38-47]. In general, neonatal intensive care is expensive, and the net cost varies depending on the intensity and duration of care needed. Preterm birth, in particular, is often associated with high costs stemming from neonatal intensive care (NICU) stay and its long-term complications. This may include both direct costs (hospitalization, parenteral nutrition, nursing time, diagnosis, treatment) and indirect costs (work loss, transportation) $[48,49]$. Therefore, it is important to consider both direct and indirect costs when discussing cost-effectiveness of any intervention. While there continues to be controversy around the cost-effectiveness of palivizumab, health care providers should try to offer the best care available for their patients when possible. This is especially true for patients vulnerable to 


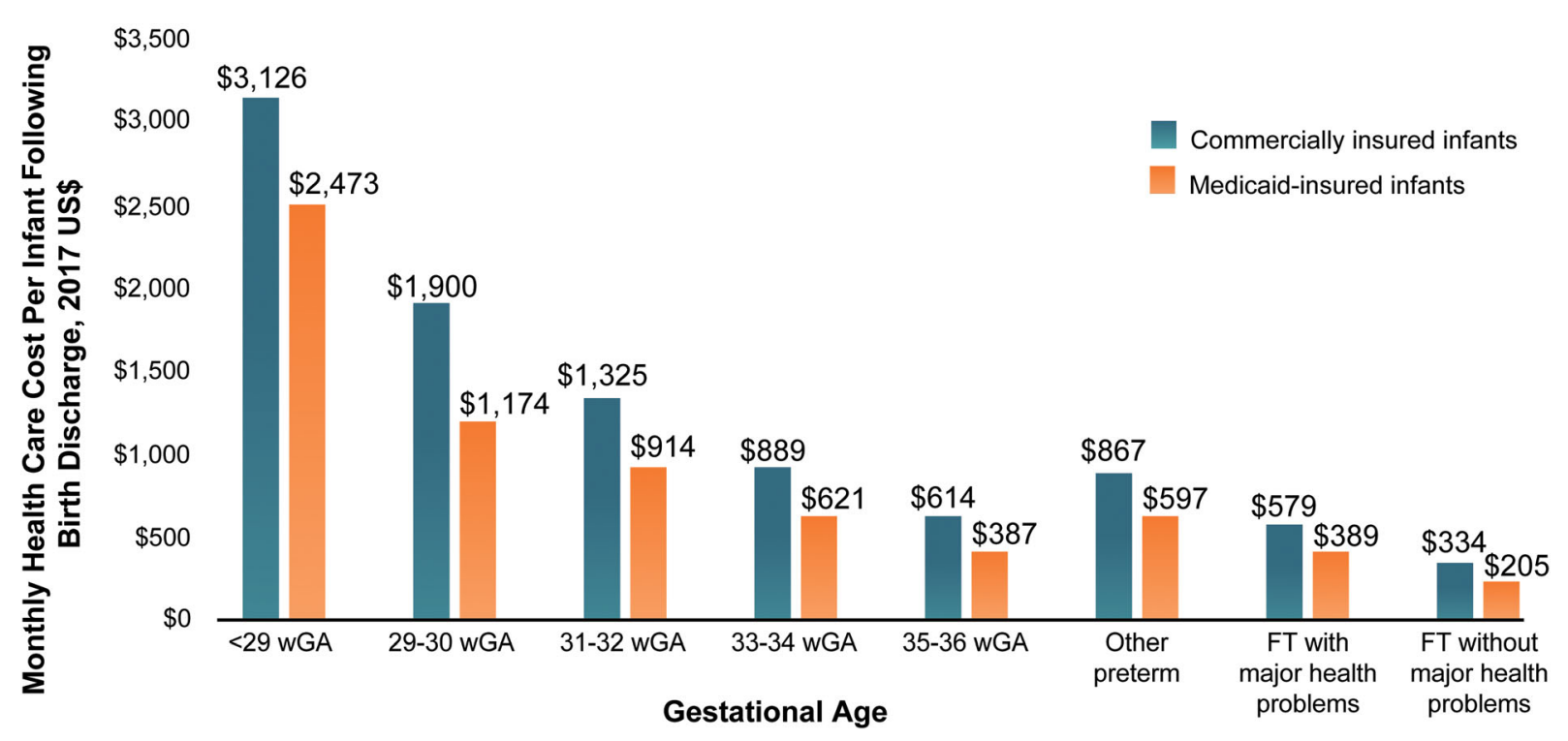

Fig. 2 Mean monthly health care cost per infant increases as the gestational age decreases [34]. FT full-term, US\$ United States dollars, wGA weeks' gestational age. Used

severe RSV disease such as premature infants and children with CLD and CHD [50].

\section{CONCLUSION}

RSV disease is a global concern and a leading cause of RSV LRTI among young children [9]. Health care resource utilization for RSV disease resulting from RSVH, its severity, management, and long-term sequelae is substantial and varies depending on age, presence of comorbidities, and sociodemographic factors across countries. Overall, the impact of RSV disease on health care systems, costs, and caregivers is concerning [6]. Alternative cost-effective therapies may be available for other diseases, but palivizumab is the only immunoprophylaxis currently available for the prevention of severe RSV disease and its associated burdens among high-risk patients [7]. The current recommendations by the American Academy of Pediatrics to limit immunoprophylaxis to preterm infants born at $<29$ wGA clearly leaves other preterm infants at risk and should be reconsidered. Direct and indirect costs associated with RSVH, including long-term sequelae, quality of life, and caregiver burden, must be considered for the medical with permission from McLaurin KK, et al. Pediatric Health Med Ther. 2019;10:21-31 (c) 2019 Dove Medical Press Limited

management of RSV among vulnerable infants $[50,51]$. Region-specific risk factors may be used to identify high-risk infants and help promote the most cost-effective use of palivizumab in the absence of long-acting monoclonal antibodies or vaccines $[16,21]$.

\section{ACKNOWLEDGEMENTS}

This supplement has been sponsored by Sobi, Inc. Robert C. Welliver served as the Guest Editor for this supplement and has the following disclosures: He has received funding from Novavax for preclinical work on their RSV vaccine in a maternal immunization study, funding from AstraZeneca for evaluation of nirsevimab, past funding from AstraZeneca for various RSV antibody studies, and from MedImmune before that. He has also received funding from Regeneron in the past for their RSV monoclonal antibody study. Finally, he is receiving NIAID (1 R41 A147787-01) funding for study of an RSV vaccine.

Funding. This study and the Rapid Service Fees were sponsored by Sobi, Inc. 
Medical Writing and Editorial Assistance. Writing and editorial support were provided by PRECISIONscientia, Inc., which were in accordance with Good Publication Practice (GPP3) guidelines and funded by Sobi, Inc.

Authorship. All named authors meet the International Committee of Medical Journal Editors (ICMJE) criteria for authorship for this article, take responsibility for the integrity of the work as a whole, and have given their approval for this version to be published.

Disclosures. Michal Young and Lynn Smitherman have nothing to disclose.

Compliance with Ethics Guidelines. This article is based on previously conducted studies and does not contain any studies with human participants or animals performed by any of the authors.

Open Access. This article is licensed under a Creative Commons Attribution-NonCommercial 4.0 International License, which permits any non-commercial use, sharing, adaptation, distribution and reproduction in any medium or format, as long as you give appropriate credit to the original author(s) and the source, provide a link to the Creative Commons licence, and indicate if changes were made. The images or other third party material in this article are included in the article's Creative Commons licence, unless indicated otherwise in a credit line to the material. If material is not included in the article's Creative Commons licence and your intended use is not permitted by statutory regulation or exceeds the permitted use, you will need to obtain permission directly from the copyright holder. To view a copy of this licence, visit http://creativecommons.org/licenses/by$\mathrm{nc} / 4.0 /$.

\section{REFERENCES}

1. Leader S, Kohlhase K. Respiratory syncytial viruscoded pediatric hospitalizations, 1997 to 1999. Pediatr Infect Dis J. 2002;21(7):629-32.
2. Collins PL, Crowe JE Jr. Respiratory syncytial virus and metapneumovirus. In: Knipe DM, Howley PM, Griffin DE, et al., editors. Fields' virology. Vol 2. 5th ed. Philadelphia, PA: Lippincott Williams \& Wilkins. 2007:1601-1646.

3. Respiratory syncytial virus. In: Kimberlin DW, editor. Red Book: 2018 Report of the Committee on Infectious Diseases. 31st ed. Elk Grove Village, IL: American Academy of Pediatrics. 2018:682-692.

4. Ackerson B, Tseng HF, Sy LS, et al. Severe morbidity and mortality associated with respiratory syncytial virus versus influenza infection in hospitalized older adults. Clin Infect Dis. 2019;69(2):197-203.

5. Griffiths C, Drews SJ, Marchant DJ. Respiratory syncytial virus: Infection, detection, and new options for prevention and treatment. Clin Microbiol Rev. 2017;30(1):277-319.

6. Díez-Domingo J, Pérez-Yarza EG, Melero JA, et al. Social, economic, and health impact of the respiratory syncytial virus: a systematic search. BMC Infect Dis. 2014. https://doi.org/10.1186/s12879014-0544-xu.

7. Simões EAF, Bont L, Manzoni P, et al. Past, present and future approaches to the prevention and treatment of respiratory syncytial virus infection in children. Infect Dis Ther. 2018;7(1):87-120.

8. SYNAGIS [package insert]. Gaithersburg, MD: MedImmune, LLC; 2017.

9. Shi T, McAllister DA, O'Brien KL, et al. Global, regional, and national disease burden estimates of acute lower respiratory infections due to respiratory syncytial virus in young children in 2015: a systematic review and modelling study. Lancet. 2017;390(10098):946-58.

10. Geoghegan S, Erviti A, Caballero MT, et al. Mortality due to respiratory syncytial virus. Burden and risk factors. Am J Respir Crit Care Med. 2017;195(1): 96-103.

11. Scheltema NM, Gentile A, Lucion F, et al. Global respiratory syncytial virus-associated mortality in young children (RSV GOLD): a retrospective case series. Lancet Global Health. 2017;5(10):e984-91.

12. Bruden DJ, Singleton R, Hawk CS, et al. Eighteen years of respiratory syncytial virus surveillance: changes in seasonality and hospitalization rates in southwestern Alaska Native children. Pediatr Infect Dis J. 2015;34(9):945-50.

13. Bont L, Checchia PA, Fauroux B, et al. Defining the epidemiology and burden of severe respiratory syncytial virus infection among infants and 
children in Western countries. Infect Dis Ther. 2016;5(3):271-98.

14. Shi T, Denouel A, Tietjen AK, et al. Global disease burden estimates of respiratory syncytial virus-associated acute respiratory infection in older adults in 2015: a systematic review and meta-analysis. J Infect Dis. 2019. https://doi.org/10.1093/infdis/ jiz059.

15. Buchward AG, Tamboura B, Tennant SM, et al. Epidemiology, risk factors, and outcomes of respiratory syncytial virus infections in newborns in Bamako, Mali. Clin Infect Dis. 2020;70(1):59-66.

16. Shi T, Balsells E, Wastnedge E, et al. Risk factors for respiratory syncytial virus associated with acute lower respiratory infection in children under five years: Systematic review and meta-analysis. J Glob Health. 2015;5(2):020416. https://doi.org/10.7189/ jogh.05.

17. Blanken MO, Paes B, Anderson EJ, et al. Risk scoring tool to predict respiratory syncytial virus hospitalisation in premature infants. Pediatr Pulmonol. 2018;53(5):605-12.

18. Glezen WP, Taber LH, Frank AL, Kasel JA. Risk of primary infection and reinfection with respiratory syncytial virus. Am J Dis Child. 1986;140(6):543-6.

19. Paynter S, Ware RS, Lucero MG, et al. Malnutrition: a risk factor for severe respiratory syncytial virus infection and hospitalization. Pediatr Infect Dis J. 2014;33(3):267-71.

20. Franklin JA, Anderson EJ, $\mathrm{Wu} \mathrm{X}$, Ambrose CS, Simoes EA. Insurance status and the risk of severe respiratory syncytial virus disease in United States preterm infants born at 32-35 weeks gestational age. Open Forum Infect Dis. 2016;3(3):ofw163. https://doi.org/10.1093/ofid/ofw163.

21. Paes B. Respiratory syncytial virus in otherwise healthy prematurely born infants: a forgotten majority. Am J Perinatol. 2018;35(6):541-4.

22. Leidy NK, Margolis MK, Marcin JP, et al. The impact of severe respiratory syncytial virus on the child, caregiver, and family during hospitalization and recovery. Pediatrics. 2005;115(6):1536-46.

23. Pokrzywinski RM, Swett LL, Pannaraj PS, et al. Impact of respiratory syncytial virus-confirmed hospitalizations on caregivers of US preterm infants. Clin Pediatr. 2019;58(8):837-50.

24. Fauroux B, Simões EAF, Checchia PA, et al. The burden and long-term respiratory morbidity associated with respiratory syncytial virus infection in early childhood. Infect Dis Ther. 2017;6(2):173-97.
25. Shi T, Ooi Y, Zaw EM, et al. Association between respiratory syncytial virus-associated acute lower respiratory infection in early life and recurrent wheeze and asthma in later childhood. J Infect Dis. https://doi.org/10.1093/infdis/jiz311.

26. Nunes C, Pereira AM, Morais-Almeida M. Asthma costs and social impact. Asthma Res Pract. 2017. https://doi.org/10.1186/s40733-016-0029-3.

27. Simões EAF, Chirikov V, Botteman M, Kwon Y, Kuznik A. Long-term assessment of healthcare utilization 5 years after respiratory syncytial virus infection in US infants. J Infect Dis. https://doi.org/ 10.1093/infdis/jiz278.

28. Chirikov VV, Simões EAF, Kuznik A, Kwon Y, Botteman M. Economic-burden trajectories in commercially insured US infants with respiratory syncytial virus. J Infect Dis. https://doi.org/10. 1093/infdis/jiz160.

29. Blanken MO, Rovers MM, Molenaar JM, et al. Respiratory syncytial virus and recurrent wheeze in healthy preterm infants. $\mathrm{N}$ Engl $\mathrm{J}$ Med. 2013;368(19):1791-9.

30. Yoshihara S, Kusuda S, Mochizuki H, Okada K, Nishima S, Simoes EA. Effect of palivizumab prophylaxis on subsequent recurrent wheezing in preterm infants. Pediatrics. 2013;132(5):811-8.

31. Anderson EJ, DeVincenzo JP, Simões EAF, et al. SENTINEL1: Two-season study of respiratory syncytial virus hospitalizations among US infants born at 29 to 35 weeks' gestational age not receiving immunoprophylaxis. Am J Perinatol. https://doi. org/10.1055/s-0039-1681014.

32. McLaurin KK, Farr AM, Wade SW, Diakun DR, Stewart DL. Respiratory syncytial virus hospitalization outcomes and costs of full-term and preterm infants. J Perinatol . 2016;36(11):990-6.

33. Paramore LC, Ciuryla V, Ciesla G, Liu L. Economic impact of respiratory syncytial virus-related illness in the US: an analysis of national databases. Pharmacoeconomics. 2004;22(5):275-84.

34. McLaurin KK, Wade SW, Kong AM, Diakun D, Olajide IR, Germano J. Characteristics and health care utilization of otherwise healthy commercially and Medicaid-insured preterm and full-term infants in the US. Pediatric Health Med Ther. 2019;10: 21-31.

35. Ledbetter J, Brannman L, Wade SW, Gonzales T, Kong AM. Healthcare resource utilization and costs in the 12 months following hospitalization for respiratory syncytial virus or unspecified bronchiolitis among infants. J Med Econ. 2019. https://doi. org/10.1080/13696998.2019.1658592. 
36. The IMpact-RSV Study Group. Palivizumab, a humanized respiratory syncytial virus monoclonal antibody, reduces hospitalization from respiratory syncytial virus infection in high-risk infants. Pediatrics. 1998;102(3 Pt 1):531-7.

37. Feltes TF, Cabalka AK, Meissner HC, et al. Palivizumab prophylaxis reduces hospitalization due to respiratory syncytial virus in young children with hemodynamically significant congenital heart disease. J Pediatr. 2003;143(4):532-40.

38. Ambrose CS, McLaurin KK. The Medicaid cost of palivizumab. J Pediatric Infect Dis Soc. 2015;4(1): 83-4.

39. Andabaka T, Nickerson JW, Rojas-Reyes MX, Rueda JD, Bacic Vrca V, Barsic B. Monoclonal antibody for reducing the risk of respiratory syncytial virus infection in children. Cochrane Database Syst Rev. $2013 . \quad$ https://doi.org/10.1002/14651858. CD006602.pub4.

40. Blanken MO, Frederix GW, Nibbelke EE, et al. Costeffectiveness of rule-based immunoprophylaxis against respiratory syncytial virus infections in preterm infants. Eur J Pediatr. 2018;177(1):133-44.

41. Borse RH, Singleton RJ, Bruden DT, Fry AM, Hennessy TW, Meltzer MI. The economics of strategies to reduce respiratory syncytial virus hospitalizations in Alaska. J Pediatric Infect Dis Soc. 2014;3(3): 201-12.

42. Ginsberg GM, Somekh E, Schlesinger Y. Should we use Palivizumab immunoprophylaxis for infants against respiratory syncytial virus? - a cost-utility analysis. Israel J Health Policy Res. 2018. https:// doi.org/10.1186/s13584-018-0258-4.

43. Luna MS, Manzoni P, Paes B, et al. Expert consensus on palivizumab use for respiratory syncytial virus in developed countries. Paediatr Respir Rev. 2018. https://doi.org/10.1016/j.prrv.2018.12.001.
44. Mac S, Sumner A, Duchesne-Belanger S, Stirling R, Tunis M, Sander B. Cost-effectiveness of palivizumab for respiratory syncytial virus: a systematic review. Pediatrics. 2019. https://doi.org/10.1542/ peds.2018-4064.

45. Mahadevia PJ, Masaquel AS, Polak MJ, Weiner LB. Cost utility of palivizumab prophylaxis among preterm infants in the United States: a national policy perspective. J Med Econ. 2012;15(5):987-96.

46. Meissner HC. Patient equity and respiratory syncytial virus Immunoprophylaxis. Israel J Health Policy Res. 2019. https://doi.org/10.1186/s13584-0190288-6.

47. Meissner HC, Kimberlin DW. RSV immunoprophylaxis: does the benefit justify the cost? Pediatrics. 2013;132(5):915-8.

48. Zupancic JAF. A systematic review of costs associated with preterm birth. In: Institute of Medicine (US) Committee on Understanding Premature Birth and Assuring Healthy Outcomes, Behrman RE, Butler AS, editors. Preterm birth: causes, consequences, and prevention. Washington (DC): National Academies Press; 2007. https://www.ncbi. nlm.nih.gov/books/NBK11391/.

49. Richardson DK, Zupancic JA, Escobar GJ, Ogino M, Pursley DM, Mugford M. A critical review of cost reduction in neonatal intensive care. II. Strategies for reduction. J Perinatol. 2001;21(2):121-7.

50. Goldstein M, Phillips R, DeVincenzo JP, et al. National Perinatal Association 2018 respiratory syncytial virus (RSV) prevention clinical practice guideline: an evidence-based interdisciplinary collaboration. Neonatol Today. 2017;12(10):1-14.

51. Wong SK, Li A, Lanctot KL, Paes B. Adherence and outcomes: a systematic review of palivizumab utilization. Expert Rev Respir Med. 2018;12(1):27-42. 